\title{
DESIGN CRITERION FOR ZCZVT SINGLE-PHASE INVERTERS WITH MAGNETICALLY-COUPLED AUXILIARY POLE
}

\author{
Mário L. S. Martins ${ }^{1}$, Carlos M. O. Stein ${ }^{1}$, José R. Pinheiro ${ }^{2}$ e Hélio L. Hey ${ }^{2}$ \\ ${ }^{1}$ PROCEN - GEPEP, Universidade Tecnológica Federal do Paraná - UTFPR \\ Pato Branco, PR, BRASIL \\ mlucio@utfpr.edu.br, cmstein@utfpr.edu.br \\ ${ }^{2}$ GEPOC, Universidade Federal de Santa Maria - UFSM \\ Santa Maria, RS, BRASIL \\ hey@ctlab.ufsm.br, renes@ctlab.ufsm.br
}

\begin{abstract}
This paper presents in detail a design methodology for Zero-Current Zero-Voltage Transition inverters with magnetically-coupled auxiliary circuit. These ZCZVT inverters accomplish favorable softswitching conditions with a magnetically coupled auxiliary voltage which is derived directly from the inverter filter inductor. It ensures no resonant auxiliary circuit, reducing circulating reactive energy. The design methodology takes into account the semiconductor requirements to ensure low switching losses on the assisted IGBT modules, which is very important to ensure the best characteristics of the ZCZVT technique. The theoretical analysis is verified experimentally by means of a $1 \mathrm{~kW}, 40 \mathrm{kHz}$ laboratory prototype. The results prove the high efficiency of the prototype implemented according to the proposed design.
\end{abstract}

Keywords - Coupled filter inductor, Inverter, Softswitching, Zero-current transition, Zero-voltage transition.

\section{INTRODUCTION}

Since it was commercially introduced in 1983 [1] continual improvements of the IGBT make it the most used power switch for many low and medium power applications [2]. More recently, enhancements in IGBT current capability and blocking voltage allowed a growing perspective to it in high power applications [3], [4]. Besides the aforementioned features, high-input impedance MOS-gate control, low forward voltage drop and fast switching have making the IGBT the predominant semiconductor in several industrial applications, especially in the field of motion control [5], where it provides the use of efficient power conversion systems [6]. Lately the IGBT is almost latch up free and its development has been mostly focused on the reduction of conduction and switching loss by optimizing the cell structure and lifetime control [7]. Indeed there is a trade-off between the IGBT turn-off time and the on state voltage drop [8] that promotes the manufactures investigations on materials, structures and fabrication processes.

In spite of a large variety of blocking voltages, most of IGBTs are available today with a $600 \mathrm{~V}$ blocking capability [9]. Depending on the manufacture the $600 \mathrm{~V}$ IGBT can be of Punch-Through (PT, or asymmetrical) or Non Punch-

Manuscript received on 27/10/2009. Revised on 15/02/2010. Accepted for publication in 25/03/2010 by recommendation of the Editor Fernando L. M. Antunes.
Through (NPT, or symmetrical) type. The PT-IGBTs use lifetime killers to enhance the trade-off between turn-off time and on state voltage drop [10]. At high temperatures, they exhibit a large current tail due to the increased carrier lifetime. On the other hand, the NPT-IGBTs technology is based on high carrier lifetime in the drift region and lower emitter efficiency. These devices do not use lifetime killers, consequently are less sensitive to temperature variations. Additionally, NPT-IGBTs [11] provide improved ruggedness, switching loss and paralleling than the PTIGBTs even though their higher on state voltage drop.

Aiming to alleviate the tail current losses and further improving power density, dynamics and EMI performance of IGBT based power converters; soft-switching techniques such as Zero-Current Transition (ZCT) [12], [13] and ZeroCurrent Zero-Voltage Transition (ZCZVT) [14], [15], [16], [17] have been used. These Resonant Transitions techniques incorporate soft-switching function into PWM converters with minimum voltage/current stresses and circulating energy. They maintain the semiconductor device ratings and converter control design as close as possible to their PWM hard-switched counterparts. This feature is a consequence of the location of the auxiliary components which are in parallel with main power path.

Once switching turn-off losses associate to turn-off time are minimized, the IGBTs trade-off can be loosen. Nevertheless, the effectiveness of the Resonant Transition techniques relay on the fact that auxiliary circuit losses do not off-set the switching losses saved from main semiconductors. The auxiliary circuit losses are quite dependent on the reactive energy produced by resonant elements that comprises the auxiliary circuit [18]. Hence, an adequate design for the auxiliary circuit is critical to ensure a superior performance. Furthermore, the auxiliary circuit design must take into account the characteristics of the semiconductors technology as well as its constraints in order to in fact reduce their switching losses.

This paper presents a design methodology for the ZCZVT inverter with magnetically-coupled auxiliary circuit [19]. This inverter presents naturally low reactive energy due to the absence of resonant elements in the auxiliary circuit. It is a consequence of the auxiliary circuit energy required for the main switches turn-off to be directly processed by the filter inductor which is magnetically-coupled with auxiliary circuit itself (Figure 1). To also ensure low auxiliary semiconductor losses it is required to consider their technology in the design of the auxiliary circuit. Therefore, the proposed design methodology also takes it into account. 


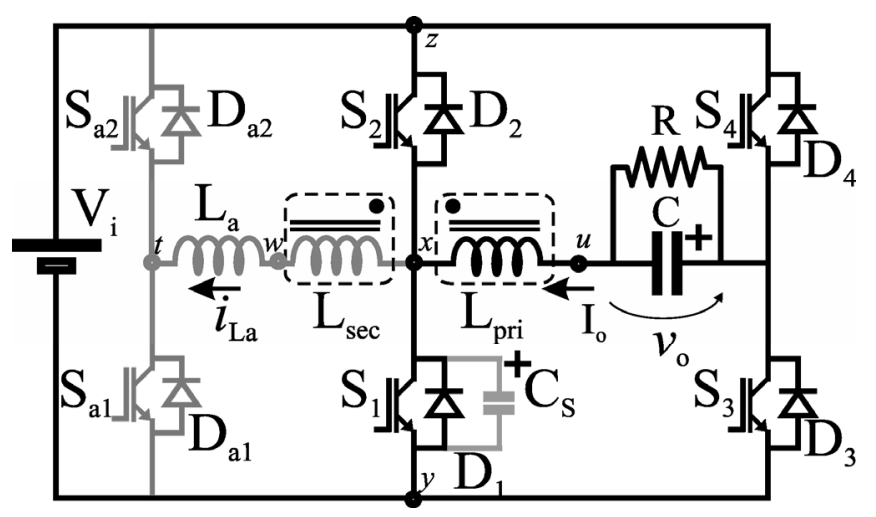

Fig. 1. ZCZVT single-phase inverter with magnetically-coupled auxiliary circuit.

\section{IGBT SWITCHING UNDER ZVS AND ZCS}

With very few exceptions, semiconductor characteristics in soft-switching mode are typically not specified by the device manufacturers. Nevertheless, various studies have already addressed the behavior of IGBT under soft-switching conditions and have revealed dissimilarities between hardand soft-switching IGBT counterparts. In soft-switching, the device shows a turn-on voltage over-shoot (in Zero-voltage mode) and a turn-off current bump (in Zero-current mode) that increase the switching power losses (vide Figure 2).

The turn-on voltage overshoot or forward recovery voltage spike, is a consequence of the finite time taken for the modulation of drift region conductivity [2] and are quite dependent on di/dt applied through the device during its turnon. The voltage spike is proportional to the temperature for PT- and NPT-IGBTs while dynamic saturation voltage, $\mathrm{V}_{\mathrm{CE}}$ (SAT) is proportional to temperature only for NPT-IGBTs Figure 2(a).

The turn-off current spike is a consequence of the sudden evacuation of the stored charge in the internal bipolar base of IGBT when forward voltage is re-applied across the device. The total recovery charge, or forward recovery charge, is the integral of current bump over time and it is a function of applied di/dt at current zero crossing, diode conduction time $\left(t_{d}\right)$, temperature and gate voltage duration $\left(t_{b}\right)$. It is evident that higher carrier density in the drift region leads to more prominent turn-off current tail. Hence, as the carrier transport is heavily dependent on carrier lifetime in PT devices, the increase in recovery charge with temperature is significantly in these semiconductors. In NPT the higher carrier lifetime even at room temperature produces an al-most independent behavior. On the other hand, to reduce the recovery charge in NPT-IGBTs during diode conduction time $\left(t_{d}\right)$ it is required to maintain the gate voltage applied until forward voltage to be re-applied Figure 2(b).

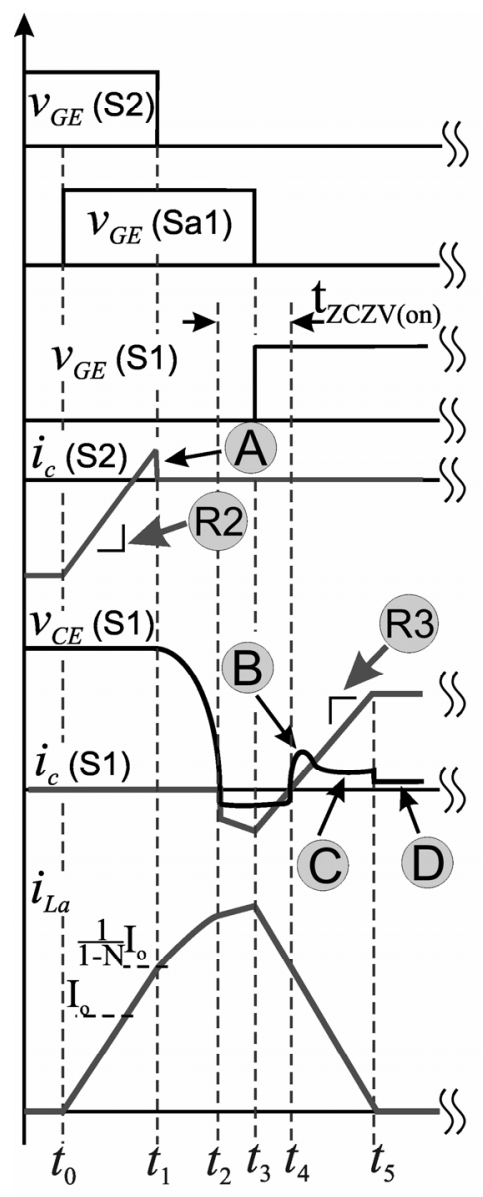

(a)

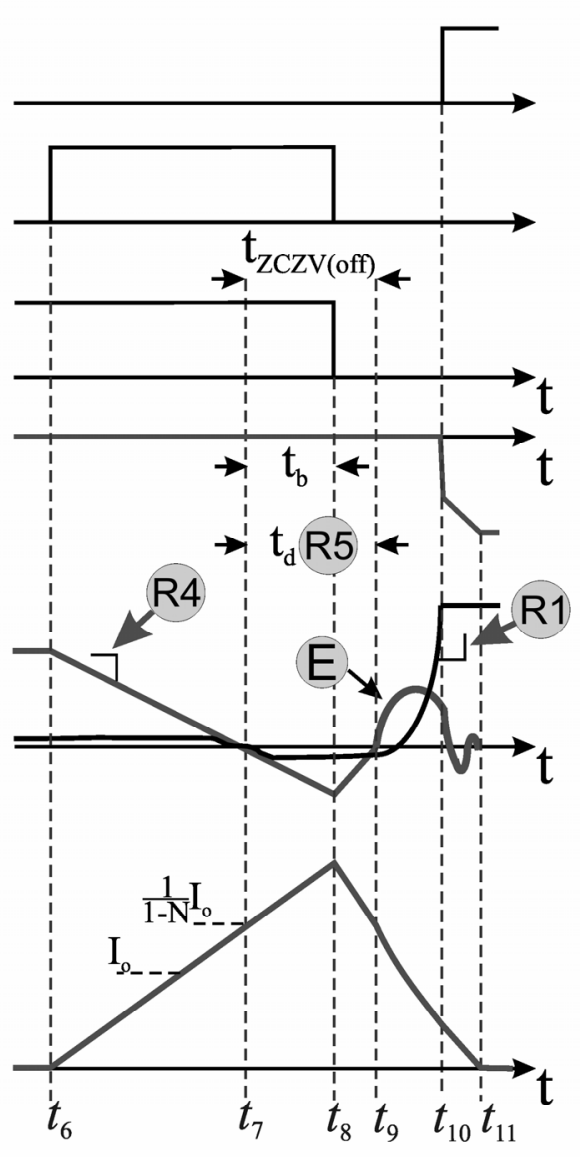

(b)

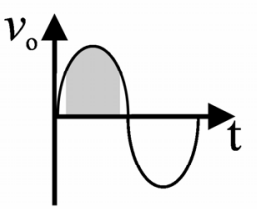

Legend:

A - diode reverse recovery charge

B - turn-on voltage overshoot

C - dynamic saturation voltage

(D) - static saturation voltage

(E) - turn-off current spike

$t_{b}$ - gatc voltagc duration

$t_{\mathrm{ZCZV}(\mathrm{on})}$ - turn-on zero-current and -voltage time $t_{\mathrm{ZCZV} \text { (off) }}$ - turn-off zero-current and -voltage time

R1 - S1 voltage rate of rise

R2 - S2 current rate of fall

R3 - $\mathrm{S} 1$ current rate of rise

R4 - S1 current rate of fall

R5 - $\left(\mathbf{t}_{\mathrm{d}}\right)$ diode conduction time

Fig. 2. Theoretical waveforms for the one ZCZVT inverter leg with magnetically-coupled auxiliary pole and detailed IGBT switching waveforms. (a) ZCZVT turn-on operation; (b) ZCZVT turn-off operation. 
The co-pack diodes that comprise the PWM pole also contributes to the switching losses since during the diode turn-off transition, its stored minority charge is removed via recombination inside the device, taking a finite time and spent a finite energy to be accomplished. The initial amount of minority charge is a function of the diode forward current and its rate of change.

The Zero-voltage and Zero-current switching condition for inverters are obtained for a PWM pole switch arrangement, as proposed in [20], by forcing the voltage of incoming switch to zero before its turn-on (likewise ZVT) and forcing the outgoing switch current to zero prior its turnoff (likewise ZCT). Controlling the current rate of change for this process, the losses through the PWM pole semiconductors can be reduced.

\section{A. Practical Switching Constrains}

As described in previous section and depicted in Figure 2, there are two phenomena that contributes to the switching losses under soft-switching conditions. They are a result of the finite time needed to establish or remove amounts of charge in the wide, light doped drift region of IGBT and diode. These physical constrains must be taken into account by the auxiliary circuit designer in order to not exacerbate their effect on switching losses. Hence, a set of design restrictions are derived from Figure 2 and specified below.

1) Restriction $R 1$ - is the maximum rate of rise of reapplied forward voltage across switch S1. It is associated with turn-off current spike and EMI performance of inverter.

2) Restriction $R 2$ - is the maximum rate of fall of negative current through switch S2. It is associated with co-packed anti-parallel diode recovery losses.

3) Restriction $R 3$ - is the maximum rate of rise of forward current through switch $\mathrm{S} 1$. It is related to forward recovery voltage spike.

4) Restriction $R 4$ - is the maximum rate of fall of forward current through switch $\mathrm{S} 1$. It is also related to turn-off current spike.

5) Restriction $R 5$ - is the minimum time of conduction for the anti-parallel of S1 that ensures that stored charge can be removed. It is also associated with turn-off current spike.

As carrier lifetime determines the time required to achieve an effective charge level, current rates through the semiconductor must comply with the following expression [21],

$$
\frac{d i}{d t}<\frac{I_{\text {rated }}}{k_{n} \tau}
$$

where:

$\tau \quad$-is the average carrier lifetime.

$k_{n} \quad$-is a constant whose value determines the level of losses demanded.

$I_{\text {rated }}$-is the rated conduction current of the semiconductor.

$d i / d t$-instantaneous rate of change of current through the semiconductor.

Hence, restrictions R2, R3 and R4 must observe expression (1).

In terms of current rise (fall) time, expression (1) may be alternatively written as follows,

$$
t_{r i}\left(t_{\text {fall }}\right)>k_{n} \tau \frac{I_{o}(t)}{I_{\text {rated }}}
$$

where:

$t_{r i} \quad$-is the semiconductor rise time.

$t_{\text {fall }} \quad$-is the semiconductor fall time.

$I_{o}(t)$ - is the semiconductor switched current level.

Restriction R5 is associated to the decay of stored charge, which can be given by considering the $t_{\text {fall }}$ in expression (2).

\section{ZCZVT INVERTER CIRCUIT ANALYSIS}

In order to simplify the analysis, the filter coupled inductor is replaced by its cantilever model with its N-port representation [22]; Load current $\left(I_{o}\right)$ is assumed to be positive with direction defined in as shown in Figure 3.

\section{A. ZCZVT inverter with magnetically-coupled auxiliary pole principles of operation}

Assuming that load current is flowing in a positive direction, the ZCZVT inverter with a magnetically-coupled auxiliary pole assumes twelve different circuit modes in one switching period, which will be briefly described as follows.

Turn-on Process:

At instant $t_{0}$ the auxiliary switch $\mathrm{S}_{\mathrm{a} 1}$ is turned on and the current starts to ramp up through auxiliary inductor $\mathrm{L}_{\mathrm{a}}$. When diode $\mathrm{D}_{2}$ is off $\left(\mathrm{t}_{1}\right)$, capacitor $\mathrm{C}_{\mathrm{s}}$ starts to discharge in a resonant fashion. At $t_{2}$ voltage $v_{\mathrm{Cs}}$ reaches zero and the difference of the secondary and primary windings current flows through diode $\mathrm{D}_{1}$, establishing the ZCZV condition. At $t_{3}, S_{a 1}$ is turned off meanwhile $S_{1}$ is turned on. From $t_{3}$ to $t_{5}$ auxiliary diode $\mathrm{D}_{\mathrm{a} 2}$ conducts the auxiliary current, demagnetizing $L_{a}$. At $t_{5}$ current $i_{L a}$ reaches zero and the turnon process is finished.

Turn-off Process:

At instant $t_{6}$ the auxiliary switch $\mathrm{S}_{\mathrm{a} 1}$ is turned on and current starts to rise up through auxiliary inductor $\mathrm{L}_{\mathrm{a}}$ in a linear fashion. The voltage applied to $\mathrm{L}_{\mathrm{a}}$ is directly reflected from the coupled inductor. At $t_{7}$ diode $D_{1}$ is turned on conducting the difference between the coupled inductor secondary and primary windings currents, establishing once again the ZCZV condition. At $t_{8}$ both switches $\left(S_{1}\right.$ and $\left.S_{a 1}\right)$

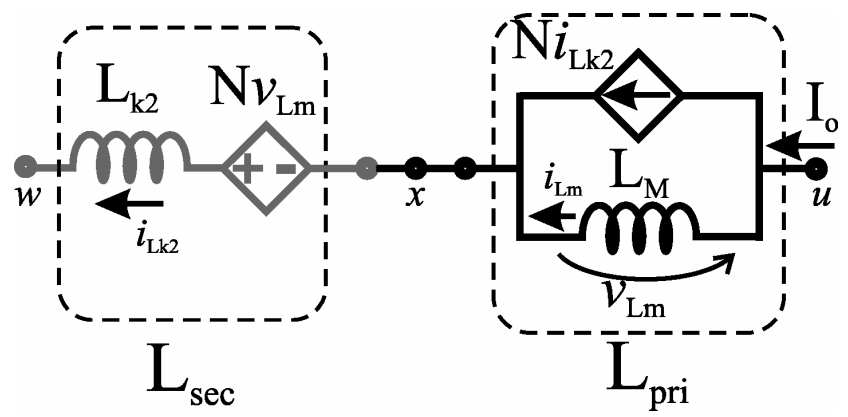

Fig. 3. Coupled inductor model for ZCZVT inverter. 
are turned off. From this instant, diode $\mathrm{D}_{\mathrm{a} 2}$ conducts the auxiliary circuit current, demagnetizing $\mathrm{L}_{\mathrm{a}}$. From $t_{9}$ to $\mathrm{t}_{10}$ capacitor $C_{s}$ is charged in a resonant way. At $t_{10} C_{s}$ is fully charged and $\mathrm{i}_{\mathrm{La}}$ continues to ramp down until it reaches zero at $\mathrm{t}_{11}$, when the turn-off process is finished.

\section{B. Derivation of Restriction $R 2$}

To evaluate the current rate of fall through the co-pack diode $\left(\mathrm{i}_{\mathrm{D}}(\mathrm{t})\right)$ of $\mathrm{S} 2$, it is required to derive it from the equivalent circuit shown in Figure 4(a). Applying the KVL to the equivalent circuit the following expression can be obtained,

$$
i_{\mathrm{D} 2}(t)=-i_{\mathrm{S} 2}(t)=i_{L m}(t)+(N-1) i_{L a}(t) .
$$

where:

$N \quad$ - is the turns ratio of coupled inductor coils $\left(N_{2} / N_{1}\right)$.

$N_{l} \quad$ - is the number of turns of primary winding.

$N_{2} \quad$ - is the number of turns of secondary winding.

$i_{L m}(\mathrm{t})$ - is the coupled inductor magnetizing current.

$i_{L a}(\mathrm{t})$ - is the current through the auxiliary inductor.

Replacing the circuit relations from the equivalent circuit of the inverter shown in Figure 4(a) and considering that $\mathrm{L}_{\mathrm{m}}$ $>\mathrm{L}_{\mathrm{a}}$, one can obtain,

$$
L_{a} \geq \frac{(N-1)\left(N V_{o}\{\theta\}-(1-N) V_{i}\right)}{\frac{d}{d t} i_{\mathrm{D} 2(M A X)}}
$$

where:

$V_{i} \quad$ - is the inverter bus voltage.

$V_{o} \quad$ - is the inverter load voltage, which is a function of the output sinusoidal angle $\{\theta\}$.

$d i_{D 2(\text { MAX })} / d t \quad-$ is the maximum rate of fall of the current through the anti-parallel diode D2.

$L_{a} \quad$ - is the auxiliary circuit inductance.

Assuming that $\theta=\omega t$, it can be seen by (3) that $i_{L m}(\mathrm{t})$ will be sinusoidal as the inverter load current $I_{o}$ is a function of angular position $\theta$. Hence, expression (4) becomes,

$$
L_{a}\{\theta\} \geq \frac{(N-1)\left(N V_{o}\{\theta\}-(1-N) V_{i}\right)}{\frac{d}{d t} i_{\mathrm{D} 2(M A X)}} .
$$

\section{Derivation of Restriction $R 3$}

The current rate of rise through switch $\mathrm{S} 1$ is derived from the equivalent circuit shown in Figure 4(b). Applying the $\mathrm{KVL}$ to the equivalent circuit the following expression can be obtained,

$$
i_{\mathrm{S} 1}(t)=i_{L m}(t)+(N-1) i_{L a}(t) .
$$

Applying the first derivative to expression (6) and solving it to $L_{a}$, it can be found that,

$$
L_{a}\{\theta\} \geq \frac{(N-1)\left(N V_{o}\{\theta\}-V_{i}\right)}{\frac{d}{d t} i_{\mathrm{S} 1(M A X)}} .
$$

where:

$d i_{S I(M A X)} / d t \quad$ - is the maximum rate of rise of the current through switch S1.

\section{Derivation of Restriction $R 4$}

The current rate of fall through switch $\mathrm{S} 1$ is derived from the equivalent circuit shown in Figure 4(c). Applying the $\mathrm{KVL}$ to the equivalent circuit the following expression can be obtained,

$$
i_{\mathrm{S} 1}(t)=i_{L m}(t)+(N-1) i_{L a}(t) .
$$

Applying the first derivative to expression (8) and solving it to $L_{a}$, it can be found that,

$$
L_{a}\{\theta\} \geq \frac{N(N-1) V_{o}\{\theta\}}{\frac{d}{d t} i_{\mathrm{S} 1(M A X)}} .
$$

\section{E. Derivation of Restriction $R 5$}

The co-pack diode $\left(D_{1}\right)$ conduction time is the time required to the recombination of minority carrier through the IGBT $p n$ junction. A rule of thumb consider that,

$$
t_{d}=2 \sim 4 t_{\text {fall }} \text {. }
$$

Depending on the semiconductor device, the diode conduction time can range from 50 to $400 \mathrm{~ns}$, as can be seen in Table I, which shown this parameter as a function of fall time for three 2-pack IGBT modules with $600 \mathrm{~V} / 40 \mathrm{~A}$ ratings.

\section{F. Effective Duty Cycle (R6)}

The voltage and current transition times impose limitations to the maximum and minimum duty cycle of the PWM pole switches, i.e., the current transference from main

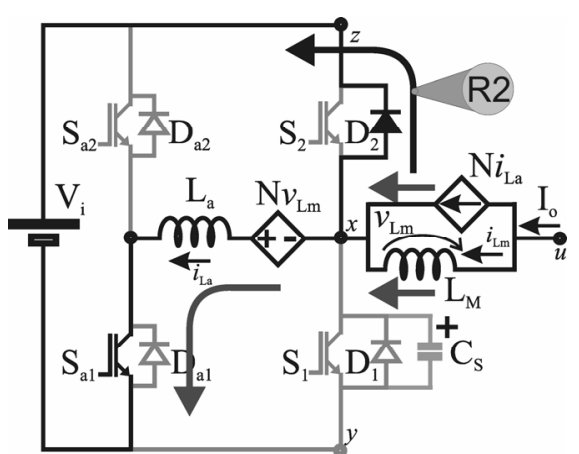

(a)

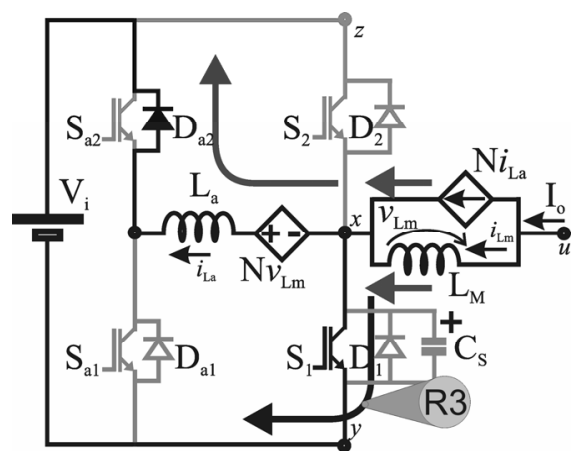

(b)

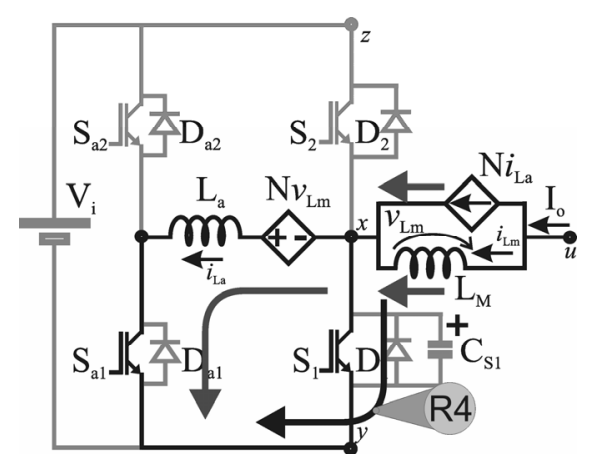

(c)

Fig. 4. Equivalent circuit for the restrictions derived from maximum current rate of change. (a) For restriction R2; (b) For restriction R3; (c) For restriction R4. 
to the auxiliary circuit limit the inverter output voltage range. The maximum output voltage is obtained from the following equation,

$$
V_{o(M A X)}=\left(T-\left(\Delta t_{\text {Loss } 1}\right)\right) V_{\text {in }} .
$$

where $\Delta t_{\text {Loss1 }}$ is the interval required to transfer the current from one co-pack diode to the auxiliary circuit and viceversa. This interval is given by,

$$
\Delta t_{\text {Loss } 1}=\left(\Delta t_{E 1}+\Delta t_{E 2}\right)+\left(\Delta t_{E 10}+\Delta t_{E 11}\right) .
$$

where the intervals $\Delta \mathrm{t}_{\mathrm{E} 1}, \Delta \mathrm{t}_{\mathrm{E} 2}, \Delta \mathrm{t}_{\mathrm{E} 10}$ and $\Delta \mathrm{t}_{\mathrm{E} 11}$ correspond to the inverter operating stage 1 , stage 2 , stage 10 and stage 11 , respectively [19].

Regardless of the very small resonant stages $\Delta \mathrm{t}_{\mathrm{E} 2}$ and $\Delta \mathrm{t}_{\mathrm{E} 10}$ the interval $\Delta t_{\text {Loss } 1}$ can be approximate by the sum of the linear stages $\Delta \mathrm{t}_{\mathrm{E} 1}$ and $\Delta \mathrm{t}_{\mathrm{E} 11}$.

Thus, the maximum possible duty cycle is expressed as,

$$
\Delta t_{\text {Loss } 1}=\Delta t_{E 1}+\Delta t_{E 11} \text {. }
$$

Substituting the time interval $\Delta \mathrm{t}_{\mathrm{E} 1}$ and $\Delta \mathrm{t}_{\mathrm{E} 11}$ from the circuit equations and also considering that $i_{L m}\left(t_{0}\right)=\mathrm{I}_{0}$, and $i_{L a}\left(t_{10}\right)=2 \mathrm{I}_{\mathrm{o}}$ it can be found that,

$$
L_{a}\{\theta\} \leq \frac{\Delta_{\text {Loss } 1}}{\left(\frac{1}{(1-N)\left(N V_{o}+(1-N) V_{i}\right)}+\frac{2}{N\left(V_{i}-V_{o}\right)}\right) I_{0}\{\theta, \phi\}}
$$

Similarly, the minimum output voltage is obtained from the following equation,
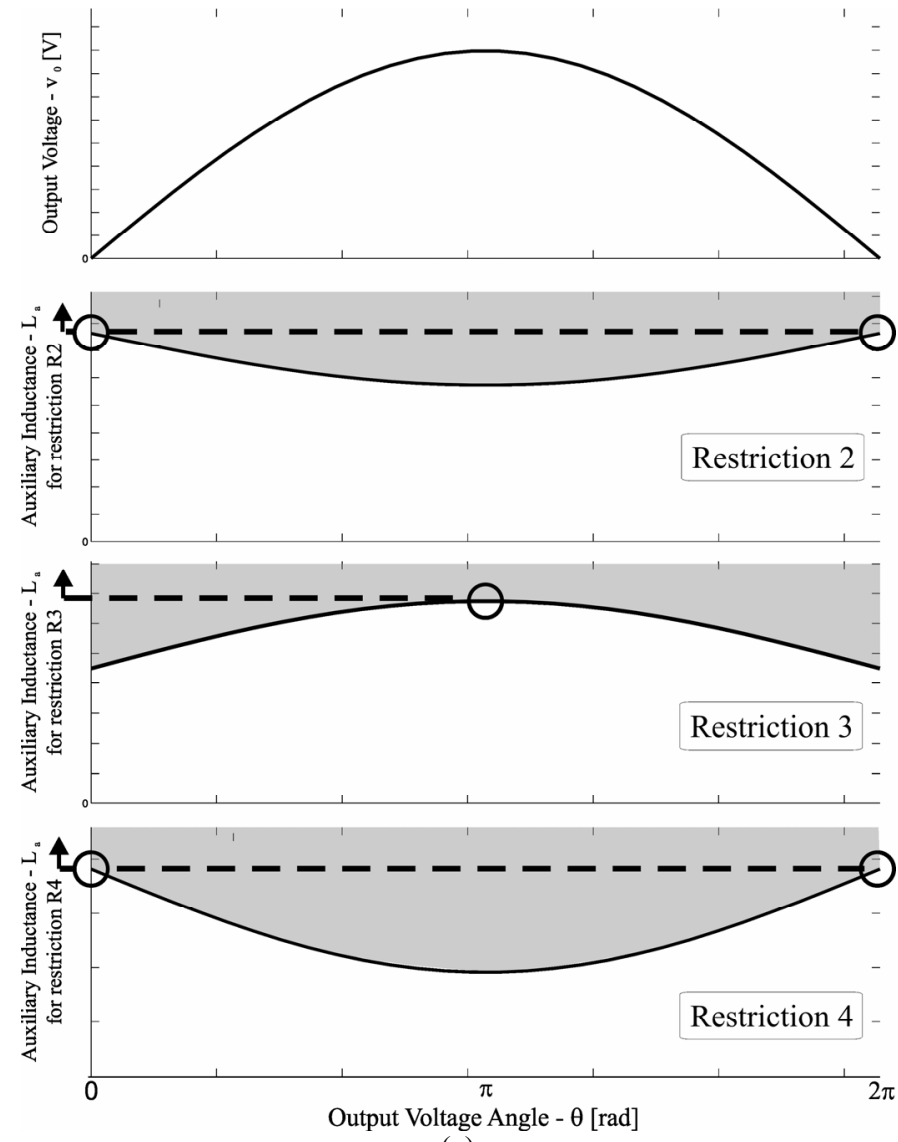

(a)

\begin{tabular}{|c|c|c|c|}
\hline Module & Nominal Ratings [A] & $t_{d}\left(\begin{array}{lll}2 & \left.t_{\text {fall }}\right)\end{array}\right)[n s]$ & $\mathbf{t}_{\mathrm{rr}}[\mathrm{ns}]$ \\
\hline VII 50-06P1 ${ }^{\#}$ & $42.5\left(25^{\circ}\right) / 29\left(70^{\circ}\right)$ & 80 & 50 \\
\hline $\mathrm{SK}^{2} 5 \mathrm{~GB} 063^{+}$ & $45\left(25^{\circ}\right) / 30\left(70^{\circ}\right)$ & 50 & 20 \\
\hline $2 \mathrm{MBI} 50 \mathrm{~N}-060 *$ & $50\left(25^{\circ}\right) /$---- & 400 & 35 \\
\hline IXYs & & & \\
\hline
\end{tabular}

Fig. 5. Restrictions for $V_{o}\{\theta\}$ and load displacement factor $\{\phi\}$.
TABLE I

2-pack IGBT modules characteristics

where $\Delta t_{\text {Loss2 }}$ is the interval required to transfer the current from the auxiliary circuit to one IGBT. This interval is given by,

$$
\Delta t_{\text {Loss } 2}=\left(\Delta t_{E 4}+\Delta t_{E 5}\right)+\left(\Delta t_{E 7}+\Delta t_{E 8}\right) .
$$

where the intervals $\Delta \mathrm{t}_{\mathrm{E} 4}, \Delta \mathrm{t}_{\mathrm{E} 5}, \Delta \mathrm{t}_{\mathrm{E} 7}$ and $\Delta \mathrm{t}_{\mathrm{E} 8}$ correspond to the inverter operating stage 4 , stage 5 , stage 7 and stage 8 , respectively [19].

Regardless of the very small stages $\Delta \mathrm{t}_{\mathrm{E} 4}$ and $\Delta \mathrm{t}_{\mathrm{E} 7}$ the interval $\Delta \mathrm{t}_{\text {Loss } 2}$ can be approximate by the sum of the linear stages $\Delta \mathrm{t}_{\mathrm{E} 5}$ and $\Delta \mathrm{t}_{\mathrm{E} 7}$.

Thus, the minimum possible duty cycle is expressed as,

$$
\Delta t_{\text {Loss } 2}=\Delta t_{E 5}+\Delta t_{E 7} \text {. }
$$

Substituting the time interval $\Delta \mathrm{t}_{\mathrm{E} 5}$ and $\Delta \mathrm{t}_{\mathrm{E} 7}$ from the circuit equations and also considering that $i_{L m}\left(t_{6}\right)=\mathrm{I}_{\mathrm{o}}$, and $i_{L a}\left(t_{3}\right)=$ $2.5 \mathrm{I}_{\mathrm{o}}$ it can be found that,

$$
L_{a}\{\theta\} \leq \frac{\Delta t_{\text {Loss } 2}}{\left(\frac{1}{(1-N) N V_{o}}+\frac{2.5}{V_{i}-N V_{o}}\right) I_{0}\{\theta, \phi\}} .
$$
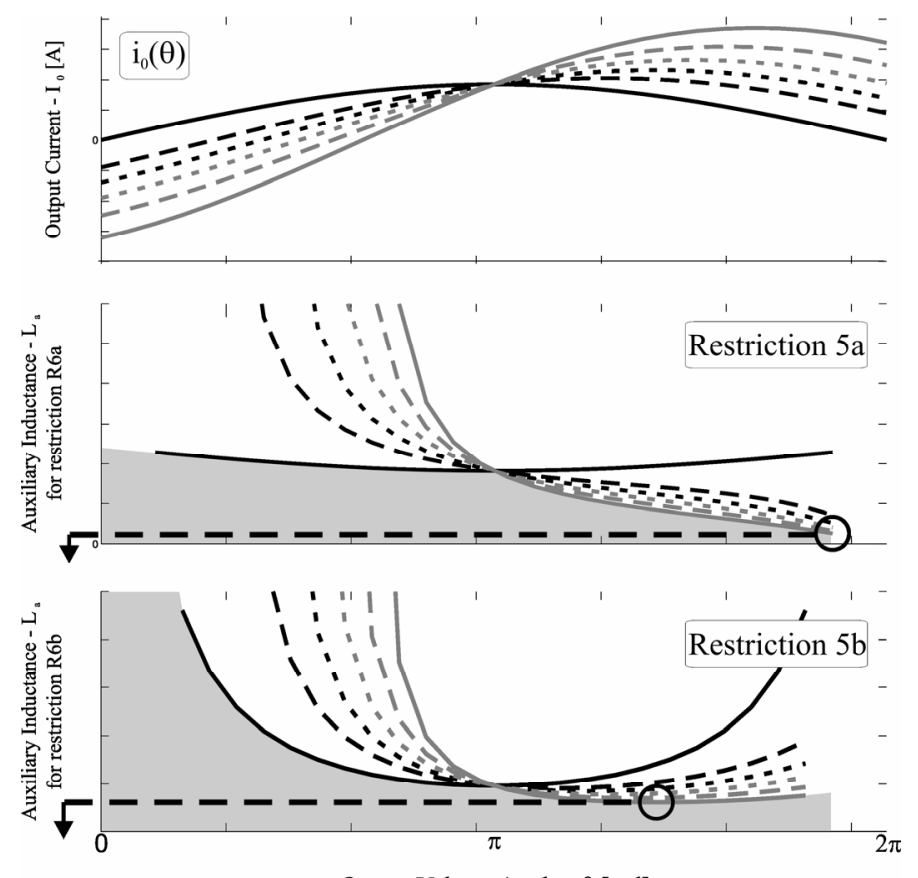

Output Voltage Angle - $\theta$ [rad]

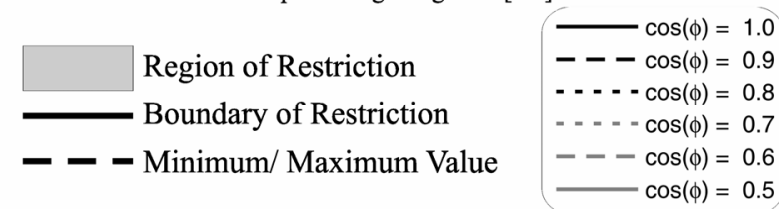

(b) 
It can be seen that restrictions $\mathrm{R} 2, \mathrm{R} 3$ and $\mathrm{R} 4$ concern the minimum value of auxiliary inductor $\left(\mathrm{L}_{\mathrm{a}(\mathrm{MIN})}\right)$ which is dependent of output voltage $V_{o}\{\theta\}$. Since the output voltage is a function of the angular frequency, the dependence of R2, $\mathrm{R} 3$ and R4 of $\theta$ is depicted in Figure 5(a). In spite of it, there is a minimum value that satisfies all restrictions, which, in turn, is a function of circuit parameters such as $V_{i}, V_{o}, N$, $d i_{D(M A X)} / d t$ and $d i_{S(M A X)} / d t$.

On the other hand, restriction R6 concerns the maximum value of auxiliary inductor $\left(\mathrm{L}_{\mathrm{a}(\mathrm{MAX})}\right)$ which is dependent of both, output voltage $V_{o}\{\theta\}$ and load displacement factor $\{\phi\}$. Since the output voltage is a function of the angular frequency, the dependence of R6 of $\theta$ and $\phi$ is depicted in Figure 5(b). Similarly, there is a maximum value of $L_{a}$ that satisfies all conditions of restriction R6, which is also a function of circuit parameters such as $V_{i}, V_{o}, N, d i_{D(M A X)} / d t$ and $d i_{S(M A X)} / d t$.

\section{AUXILIARY CIRCUIT DESIGN CONSIDERATIONS}

To design the auxiliary circuit parameters and components, according to the restrictions defined in Section III, it is required to determine the maximum current rate of change for the IGBT and co-pack diodes that form the PWM pole switches. With these parameters defined, it is also necessary to take into account the inverter specifications that concern the load requirements and other system constrains like the switching frequency and DC bus voltage.

\section{A. Maximum Current Rate of Change of Semiconductors}

In order to establish a graphical relation of the auxiliary inductor value $\left(L_{a}\right)$ as a function of the coupled inductor turns ratio $(N)$, it is required to define the maximum current rate of change through the semiconductors using the following expressions.

The maximum allowable current rate of fall (restriction R2) through the co-pack diode can be obtained from the following expression,

$$
\frac{d}{d t} i_{\mathrm{D} 2(M A X)}\{R 2\}=\frac{I_{o(M A X)}}{t_{r r}{ }^{2}}\left(2.8 \times 10^{-6} V_{i}\right)^{2}
$$

where $t_{r r}$ is the reverse recovery time, given by,

$$
t_{r r}=\frac{2 Q_{r r}}{I_{r r}}
$$

And $Q_{r r}$ is the reverse recovery charge and $I_{r r}$ is the maximum reverse current.

Hence,

$$
\frac{d}{d t} i_{\mathrm{D} 2(M A X)}\{R 2\}=282 \mathrm{~A} / \mu \mathrm{s}
$$

The maximum allowable current rate of rise (restriction R3) through the IGBT can be obtained from the following expression,

$$
\frac{d}{d t} i_{\mathrm{S} 1(M A X)}\{R 3\}=\frac{I_{\text {Nominal }}}{k_{n} \tau}
$$

where $\mathrm{k}_{\mathrm{n}}$ is set to one; and $\tau$ is set to a general value defined as $1 \mu \mathrm{s}$ [23].

Thus,

$$
\frac{d}{d t} i_{\mathrm{S} 1(M A X)}\{R 3\}=30 \mathrm{~A} / \mu \mathrm{s}
$$

The maximum allowable current rate of fall (restriction 4) through the IGBT can be estimated to be the same as for the co-pack diode, and thus,

$$
\frac{d}{d t} i_{\mathrm{S} 1(M A X)}\{R 4\} \approx \frac{I_{o(M A X)}}{t_{f}}
$$

where $t_{f}$ is set to the sum of $t_{\text {fall }}$ and $t_{\text {doff }}$ of the IGBT module.

This way,

$$
\frac{d}{d t} i_{\mathrm{S} 1(M A X)}\{R 4\}=40.5 \mathrm{~A} / \mu \mathrm{s}
$$

\section{B. Duty-Cycle loss and its restrictions}

To establish a graphical relation of the auxiliary inductor value $\left(L_{a}\right)$ as a function of the coupled inductor turns ratio $(N)$, it is required to also define the maximum and minimum possible duty cycles, which are given by (26) and (27), respectively.

$$
\Delta t_{\text {Loss } 1}=D_{M A X}=k_{M} M_{a} T_{S} \approx 12.5 \mu s
$$

where:

$k_{M} \quad$ - is a constant of allowed duty-cycle loss, it varies from 0 to 1 .

$$
\begin{aligned}
& M_{a} \quad \text { - is the modulation index }\left(M_{a}=V_{o(\operatorname{Max})} / V_{i}\right) . \\
& T_{s} \quad \text { - is the switching period }\left(T_{s}=1 / f_{s}\right) .
\end{aligned}
$$

For this analysis, $\mathrm{T}_{\mathrm{s}}=25 \mu \mathrm{s}, M_{a}=0.49$ and $k_{M}$ is set to 1 . and

$$
\Delta t_{\text {Loss } 2}=D_{\text {Min }}=k_{D} T_{S}=7.5 \mu \mathrm{s}
$$

where:

$k_{D} \quad$ - is a constant of allowed minimum duty-cycle, it varies from 0 to 1 .

For this analysis $k_{D}$ is set to 0.3 .

\section{Inverter Design Constrains}

The design parameters for the ZCZVT inverter are defined in Table II. It is considered that the inverter feeds a resistive load and the output filter is a second order (LC) low pass filter. The output voltage frequency is $60 \mathrm{~Hz}$ and the switching frequency is $40 \mathrm{kHz}$.

\section{Auxiliary Circuit Parameters}

Using the semiconductor parameters described in Table I and the ZCZVT inverter parameters described in Table II, for a load with a displacement factor of 0.8 , the graphs of Figure 6 are obtained. The curves traced in Figure 6 shown the maximum and minimum values for inductance $L_{a}$ in function of turns ratio $N$. it can be seen that curves for minimum values are slightly influenced by the semiconductor parameters.

By Figure 6 it can be seen that any value below the boundary of $\min . / \max$. duty-cycle complies with restrictions (14) and (18). Values above this boundary will produce a bed operation of the auxiliary circuit and may damage the circuit. It should be highlighted that the auxiliary circuit does not operate at low output voltages. The minimum voltage permitted for its operation is also defined by $D_{\text {Min }}$. 
TABLE II

ZCZVT inverter parameters

\begin{tabular}{cc}
\hline Parameter & Value \\
\hline Load Power & $1 \mathrm{~kW}$ \\
\hline Bus Voltage $\left(V_{i}\right)$ & $360 \mathrm{~V}$ \\
\hline Output Voltage $\left(V_{o}\right)$ & $127 \mathrm{~V}_{\mathrm{rms}}$ \\
\hline Switching Frequency $\left(f_{s}\right)$ & $40 \mathrm{kHz}$ \\
\hline Output filter THD & $5 \%$ \\
\hline Filter inductor $(\mathrm{L})$ & $1.0 \mathrm{mH}$ \\
\hline Filter capacitor $(\mathrm{C})$ & $20 \mu \mathrm{F}$ \\
\hline
\end{tabular}

On the other hand, any value above the boundary of maximum $\mathrm{di} / \mathrm{dt}$ (for the respective semiconductor) complies with restrictions (5), (7) and (9). Values below this boundary will produce excessive switching losses in the IGBT module, even at ZCZVT conditions, which is detailed in Section II.

Hence the choice of the auxiliary circuit parameters between these boundaries permits a better performance of the ZCZVT inverter.

In order to reduce the copper losses in the coupled inductor, which are proportional to the secondary winding copper length, the turns ratio $N$ is chosen as small as possible, hence, $N=0.3$. Similarly, inductor $L_{a}$ is defined as the smallest one, i. e., $L_{a}=7.14 \mu \mathrm{H}$, i.e., it is set on the boundary of max. di/dt for the SK45GB063 module.

\section{EXPERIMENTAL RESULTS}

To evaluate the effectiveness of the design methodology presented in Section IV, a $1 \mathrm{~kW}, 40 \mathrm{kHz}$ laboratory prototype has been built its and experimental results are given in Fig. 7. The prototype diagram is the same as shown in Figure 1. The H-bridge ZCZVT inverter with magnetically-coupled auxiliary circuit operate with discontinuous PWM modulation in such a way that only one inverter leg commutates at high frequency $(40 \mathrm{kHz})$ [19]. In the breadboard prototype, both inverter legs are implemented with a 2-pack IGBT module SK45GB063 from Semikron. Since the auxiliary circuit handles a fraction of the inverter power, the auxiliary switches have been implemented with

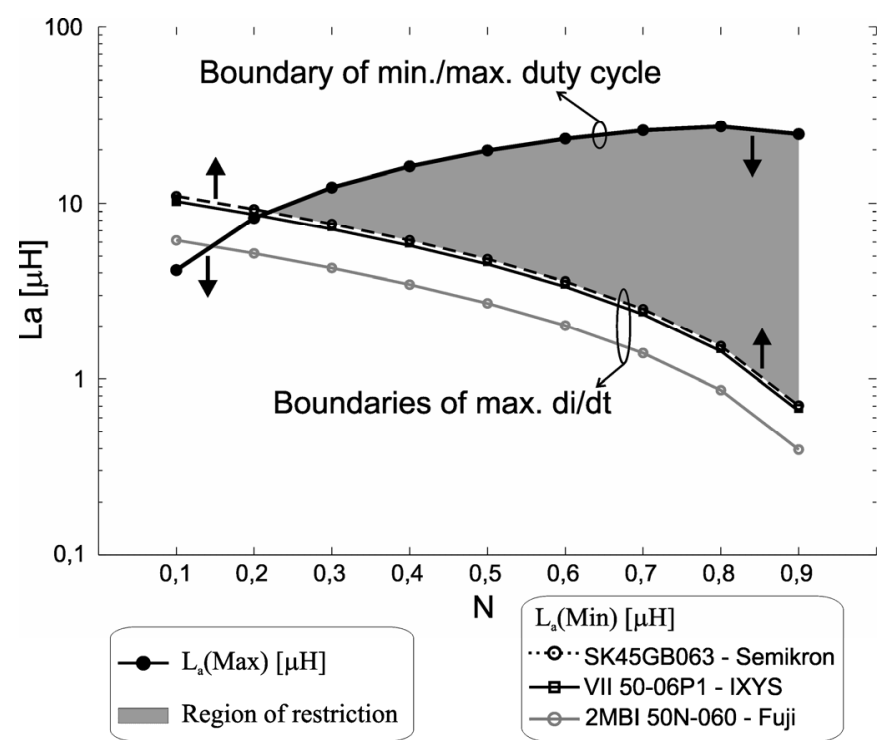

Fig. 6. Auxiliary circuit parameters $L_{a}$ in function of $N$ for different IGBT modules.
MOSFETs (IRFP460) semiconductors that are suited to fast switching $(80 \mathrm{kHz})$ with very low switching losses. To avoid the conduction of the intrinsic slow switching body diode, an arrangement of two Hyperfast diodes (RHR870) is used. A

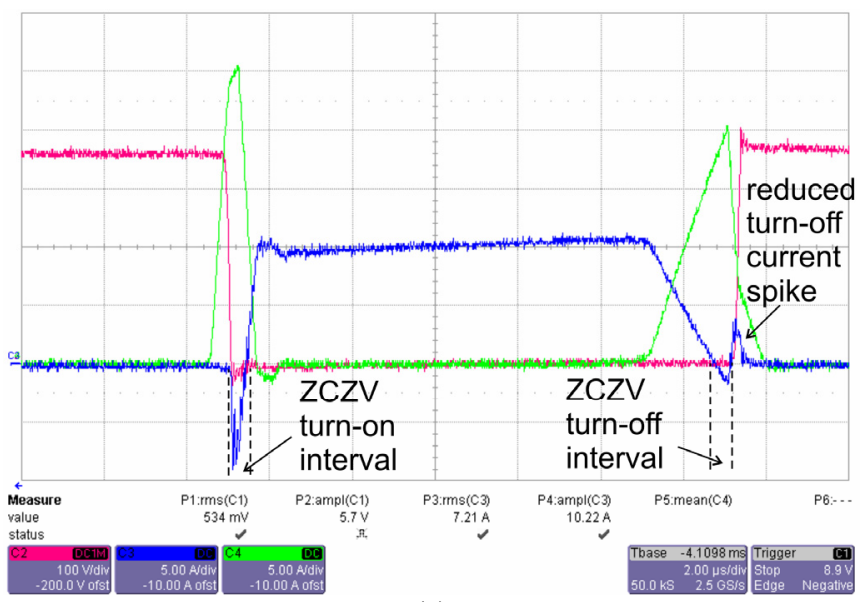

(a)

Scales: $v_{C E} 100 \mathrm{~V} / \mathrm{div} ; i_{C} 5 \mathrm{~A} / \mathrm{div} ; \mathrm{i}_{\mathrm{La}} 5 \mathrm{~A} / \mathrm{div}$

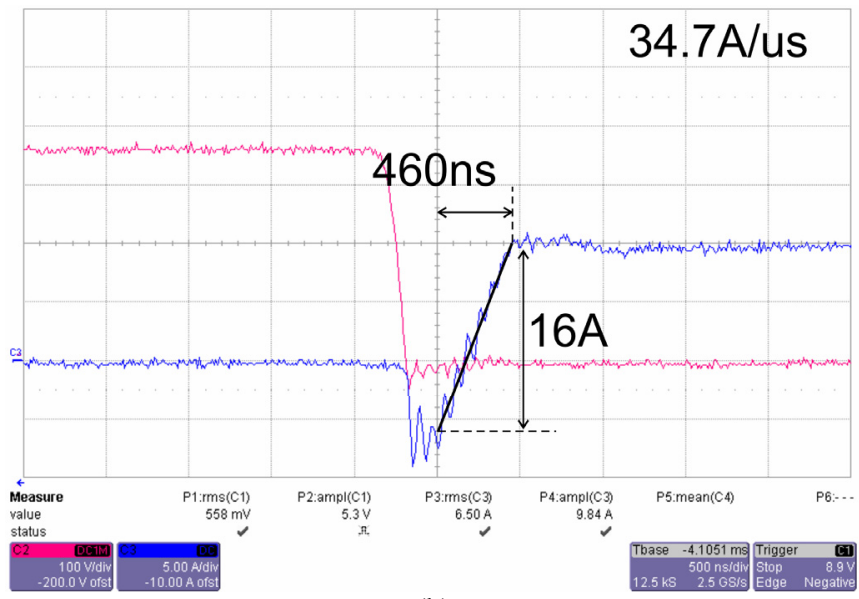

(b)

Scales: $v_{C E} 100 \mathrm{~V} / \mathrm{div} ; i_{C} 5 \mathrm{~A} / \mathrm{div}$

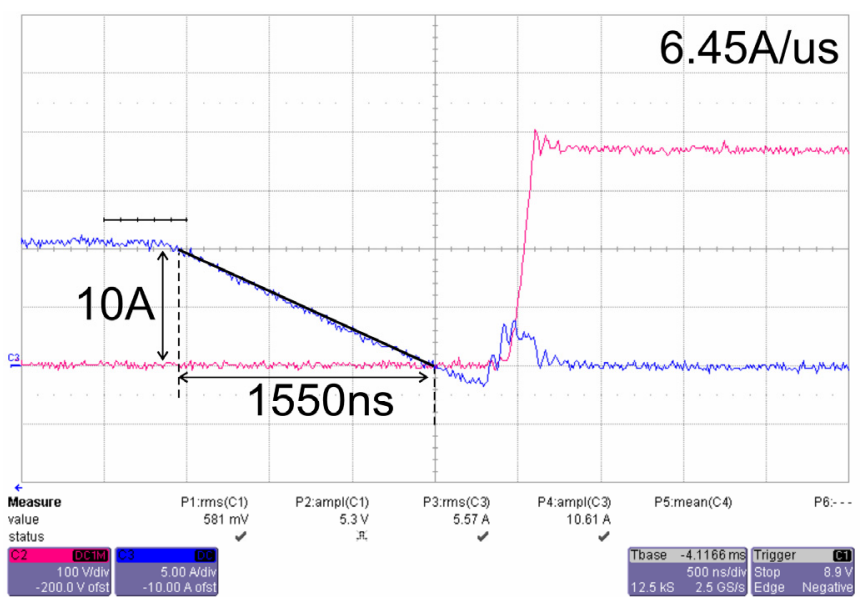

(c)

Scales: $v_{C E} 100 \mathrm{~V} / \mathrm{div} ; i_{C} 5 \mathrm{~A} / \mathrm{div}$

Fig. 7. Experimental results for ZCZVT inverter prototype. (a) Main switch waveforms for a switching period. (b) Detail of main switch turn-off process. (c) Detail of main switch turn-on. 


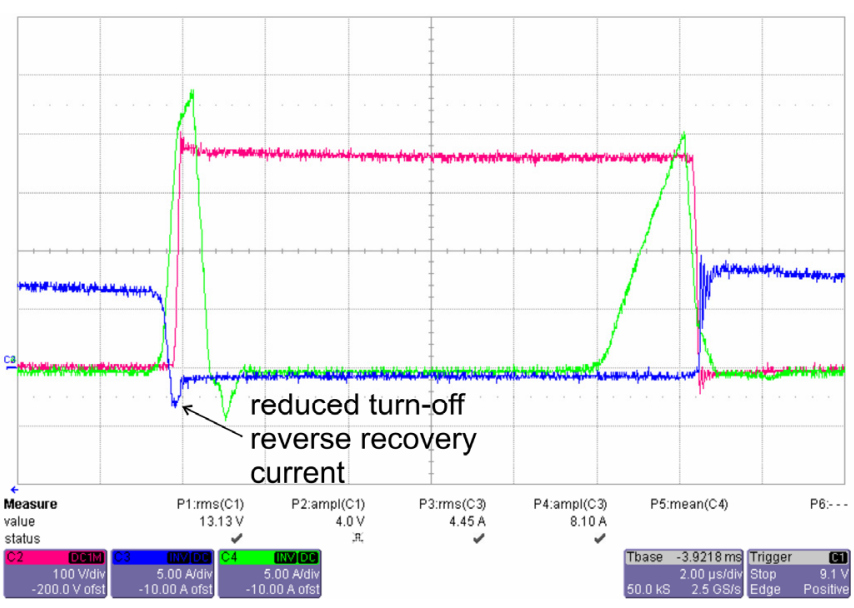

Fig. 8. Co-pack diode waveforms for a switching period.

Scales: $v_{C E} 100 \mathrm{~V} / \mathrm{div} ; i_{F} 5 \mathrm{~A} / \mathrm{div} ; \mathrm{i}_{\mathrm{La}} 5 \mathrm{~A} / \mathrm{div}$

series diode block the reverse current through the MOSFET and other diode bypass the series connection to provide bidirectional current capability. The coupled inductor is accomplished with an EE-69/33/52 shape E Ferrite Core wrapped with two 30/9 copper coils. A saturable Toshiba SA $14 \times 8 \times 4.5$ core is connected in series with the coupled inductor secondary winding to prevent ringing in the auxiliary semiconductor switches.

Figure 7(a) shows a PWM pole main switch waveforms and the auxiliary inductor current. From the waveforms it can be seen that the auxiliary circuit produces very low reactive energy, as the inductor current deviates the PWM pole current in a linear fashion. The Zero-Current and ZeroVoltage conditions intervals for both turn-on and turn-off transitions are highlighted with vertical dotted lines in the figure. It is also pointed out the existence of a current spike right after the switch turns off. It can be minimized enlarging the ZCZV turn-off time, enabling a better reduction of the stored charge in the internal bipolar base of IGBT. Figure 7(b) shows a detail of the switching turn-on process. It can be seen that the current rate of change is about $34.7 \mathrm{~A} / \mu \mathrm{s}$, which is very close to the theoretical value defined by expression (23). On the other hand, Figure 7(c) shows that the current rate of change for the turn-off process is about $6.45 \mathrm{~A} / \mu \mathrm{s}$. The theoretical value for the turn-off current rate of change is approximately six times higher. The current through the module co-pack diode is viewed in Figure 8. It can be seen that the diode turns off with a reduced di/dt. Nevertheless, there is a small reverse recovery current (about 3A) which can be minimized reducing the restriction defined by expression (21).

Hence, from the experimental results, it can be concluded that the restrictions that was took into account during the auxiliary circuit design have been achieved. It should be considered that the design methodology make use of ideal components, such as the coupled inductor, which coupling factor is assumed to be equal to its turns ratio, disregarding the primary and secondary leakage inductances.

The efficiency curve obtained from the ZCZVT inverter laboratory prototype is depicted in Figure 9, along with a dissipative snubber inverter prototype (Undeland snubber)

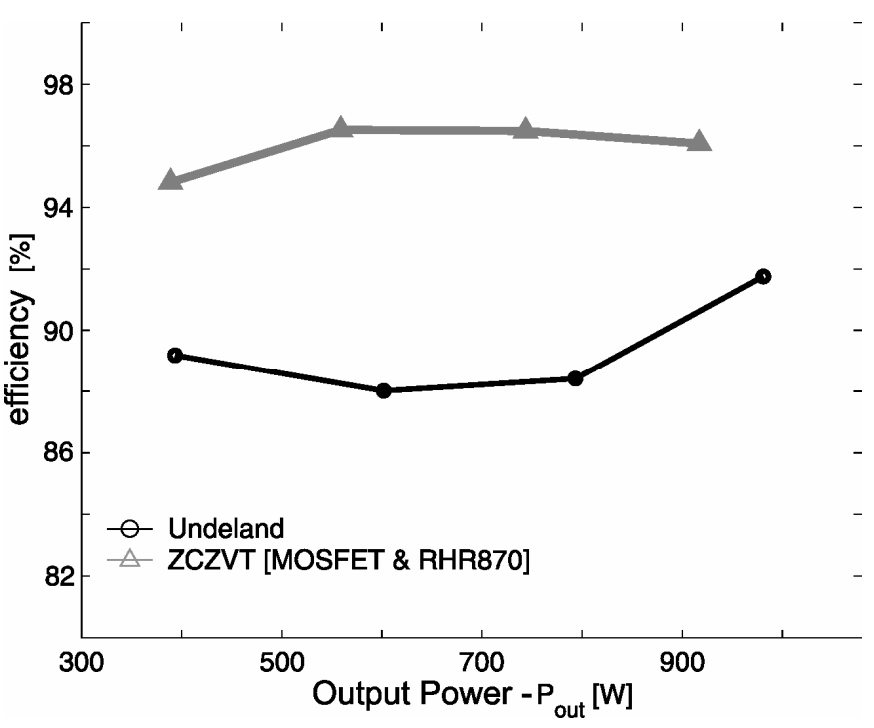

Fig. 9. Efficiency curves.

with same specifications. It can be seen that the ZCZVT inverter presents higher efficiency for the entire load range, achieving $96 \%$ at full load. It also can be seen from Figure 9 that, the variable timing control of the auxiliary switches and the low reactive energy results in high efficiency values, even in light load conditions, as the efficiency curve of the ZCZVT inverter is kept above $96 \%$ from half to full-load.

\section{CONCLUSIONS}

The ZCZVT technology potentially can improve the efficiency of power electronics converters, reducing significantly the switching losses. Nevertheless it only is effective if the semiconductors physical limitations are observed. This way, this paper presented a detailed design methodology for the ZCZVT inverters with magneticallycoupled auxiliary circuit. It takes into account the semiconductor current rates of change to ensure low switching losses to the assisted devices, and inverter operating limits. Complete calculus and analysis of the auxiliary circuit parameters are presented and discussed counting different IGBT module technologies.

The theoretical analysis is verified experimentally by means of a $1 \mathrm{~kW}, 40 \mathrm{kHz}$ laboratory prototype. The results are compared to a dissipative snubber inverter prototype with similar specifications and prove the high efficiency of the prototype implemented according to the proposed design.

The ZCZVT inverter prototype presented higher efficiency for the entire load range, achieving $96 \%$ at full load. It also can have been demonstrated that the variable timing control of the auxiliary switches and the low reactive energy results in high efficiency values, even in light load conditions, as the efficiency curve of the ZCZVT inverter is kept above $96 \%$ from half to full-load.

\section{ACKNOWLEDGEMENT}

The authors would like to express their gratitude to CAPES, CNPq (n ${ }^{\circ} 481195 / 2007-6,478154 / 2009-7$ and 554103/20109), FAPERGS and "Secretaria de Estado da Ciência, Tecnologia e Ensino Superior - SETI" for their financial 
support. They also would like to thank Toshiba do Brasil, Thornton Inpec Eletrônica Ltda, Icotron (an EPCOS company) and XILINX for material support.

\section{REFERENCES}

[1] B.J. Baliga, et al, "The Insulated Gate Transistor (IGT): A New Power Switching Device", in Proc. of IEEE Industry Application Society Annual Meeting - IAS83, pp. 794-803.

[2] S. Pendharkar, K. Shenai, "Zero Voltage Switching Behavior of Punchthrough and Nonpunchthrough Insulated Gate Bipolar Transistors (IGBTs)", IEEE Transactions on Electron Devices, vol. 45, no. 8, pp. 1826-1835, August 1998.

[3] N.A. Moguilnaia, et al, "Innovation in Power Semiconductor Industry: Past and Future", IEEE Transactions on Engineering Management, vol. 52, no 4, pp. 429-439, 2005.

[4] D. Vinnikov, "Some Design Considerations for the 6.5 $\mathrm{kV}$ IGBT-Based Half-bridge DC/DC Converter", Eletrônica de Potência, vol. 13, no. 2, pp. 55-60, May 2008.

[5] V.K. Khana, The Insulated Gate Bipolar Transistor IGBT: Theory and Design, IEEE Press, Piscataway, NJ, 2003.

[6] W.R. Araújo, L.C. Leite, S.G. Moreira, V.M. Pereira, A.R. da Silva Jr., "Aplicação de Técnicas de Inteligência Artificial visando Eficiência Energética e Estimação de Parâmetros em Sistemas Motrizes Industriais", Eletrônica de Potência, vol. 13, no. 4, pp. 209-216, November 2008.

[7] L. Lorenz, A. Mauder, J.G. Bauer, "Rated Overload Characteristics of IGBTs for low voltage and high voltage devices", in Proc. of the $36^{\text {th }}$ IEEE Industry Applications Society Annual Meeting, IAS 2001, pp. 1066-1073.

[8] B.J. Baliga, "Trends in Power Semiconductor Devices", IEEE Transactions on Electron Devices, vol. 43, no. 10, pp. 1717-1731, October 1996.

[9] B.J. Baliga, "The future of power semiconductor device technology", in Proc. of IEEE, vol. 89, no. 6, pp. 822$832,2001$.

[10] S. Lefebvre, F. Forest, "Turn-off Analysis of The IGBT used in ZCS Mode", in Proc. of the 6th International Symposium on Power Semiconductor Devices \& ICs., pp. 99-104, 1994.

[11]G. Miller, J. Sack, “A new concept for a non punch through IGBT with MOSFET like switching characteristics", in Proc. of the IEEE 20th Annual Power Electronics Specialists Conference, PESC '89, pp. 21-25, 1989.

[12] G. Hua, et al, "Novel zero-current-transition PWM converters", IEEE Transactions on Power Electronics, vol. 9, no. 6, pp. 601-606, 1994.

[13] G. Hua, C.S. Leu, F. C. Lee, "Soft-Switching Techniques in PWM Converters", IEEE Transaction on Industrial Electronics, vol. 42, no. 6, pp. 595-603, 1995.

[14]C.M.O. Stein, H.L. Hey, "Conversor Boost ZCZVT PWM”, Eletrônica de Potência, vol. 3, no. 1, pp. 35-41, November 1998.
[15] C.M.O. Stein, H.L. Hey, “A True ZCZVT Commutation Cell for PWM Converters", IEEE Transactions on Power Electronics, vol. 15, no. 1, pp. 185-193, 2000.

[16] M.L. da S. Martins, J.L. Russi, J.R. Pinheiro, H.L. Hey, "Zero-Current Zero-Voltage Transition PWM Converters with Magnetically Coupled Auxiliary Circuit", Eletrônica de Potência, vol. 13, no. 4, pp. 204208, November 2008.

[17] C.A. Gallo, F.L. Tofoli, E.A.A. Coelho, L.C. de Freitas, V.J. Farias and J.B. Vieira Jr., "A ZCZVT PWM threelevel full-bridge McMurray inverter", in Proc. of 35th Annual Power Electronics Specialists Conference, 2004. PESC 04. 2004, pp. 4803-4807, Vol.6.

[18]X. Jing, D. Boroyevich, "Comparison between a novel zero-switching-loss topology and two existing zerocurrent-transition topologies", in Proc. of IEEE Applied Power Electronics Conference APEC '00, Vol. 2, pp. 1044-1048, 2000.

[19] M.L. Martins, et al, "Novel Resonant Transition PWM Inverters: Synthesis and Analysis", in Proc. of the 37th IEEE Power Electronics Specialists Conference, PESC '06, 2700-2706, 2006.

[20] C.M.O. Stein, et al, "Zero-Current and Zero-Voltage Soft-Transition Commutation Cell for PWM Inverters", IEEE Transactions on Power Electronics, vol. 19, no. 2, pp. 396-403, 2004.

[21] C.M. Johnson and V. Pickert, "Three-phase softswitching voltage source converter for motor drives. Part 2: Fundamental limitations and critical assesment", in IEE proc. of Electric Power Applications, 1999, vol. 146, no2, pp. 155-162.

[22]D. Maksimovic, R. Erickson, "Modeling of crossregulation in multiple-output flyback converters" in Proc. of $14^{\text {th }}$ IEEE Annual Applied Power Electronics Conference and Exposition, APEC '99, vol. 2, pp. 10661072.

[23]J.G. Kassakian, M.F. Schlecht, G.C. Verghese, Principals of Power Electronics, Addison-Wesley Publishing Company, Massachusetts, 1991.

\section{BIOGRAPHIES}

Mário Lúcio da Silva Martins was born in Palmeira das Missões, RS, Brazil, in 1976. He received the B.S., M.S. and $\mathrm{Ph} . \mathrm{D}$. degrees in electrical engineering from the Federal University of Santa Maria, Santa Maria, Brazil in 1999, 2002 and 2008, respectively.

In 2006, he joined the Department of Electronics of the Federal University of Technological - Parana, Pato Branco, Brazil, where he is currently a Professor, lecturing Power Electronics and Electrical Circuit Analysis for the under and pos-graduating courses of Electrical Engineering. His research interests include high-frequency power converter topologies for DC and AC power sources, VSD drives and renewable sources.

Dr. Martins is a member of the Brazilian Power Electronics Society (SOBRAEP) and IEEE Industry Applications, Power Electronics and Industrial Electronics Societies. Dr. Martins was the recipient of the Second Prize Paper Award from the Industrial Power Converter 
Committee of the IEEE Industry Applications Society (IAS) at the 2005 IAS Annual Meeting.

Carlos Marcelo de O. Stein was born in Santiago, RS, Brazil, in 1970. He received the B.S., M.S. and Ph.D. degrees in electrical engineering from the Federal University of Santa Maria, Santa Maria, Brazil in 1996, 1997 and 2003, respectively.

Since 2003, he has been with the UTFPR, Pato Branco, Parana, Brazil, where he is currently a Professor. His research interests include high-frequency power converter topologies, power-factor-correction techniques, power supplies, and soft-switching techniques.

Dr. Stein is a member of the Brazilian Power Electronics Society (SOBRAEP).

José Renes Pinheiro was born in Santa Maria, Brazil, in 1958. He received the B.S. (1981) degree from the Federal University of Santa Maria, Santa Maria, Brazil, and the M.S. (1984) and Ph.D. (1994) degrees from the Federal University of Santa Catarina, Florianópolis, Brazil, all in electrical engineering.

Since 1985, he has been a Professor at the Federal University of Santa Maria, where, in 1987, he founded the
Power Electronics and Control Research Group (GEPOC). From 2001 to 2002, he was with the Center for Power Electronics Systems, Virginia Polytechnic Institute and State University, Blacksburg, as a Postdoctoral Research Scholar.

Dr. Pinheiro is a member of the Brazilian Power Electronics Society, Brazilian Automatic Control Society, and several IEEE societies.

Hélio Leães Hey was born in Santa Maria, Brazil, in 1961. He received the B.S. (1985) degree from the Catholic University of Pelotas, Pelotas, Brazil, and the M.S. (1987) and Ph.D. (1991) degrees from the Federal University of Santa Catarina, Florianopolis, Brazil.

From 1989 to 1993, he was with the Federal University of Uberlândia, Uberlândia, Brazil. Since 1994, he has been with the Power Electronics and Control Research Group (GEPOC), Federal University of Santa Maria, where he is currently a Professor. From 1995 to 1999, he was Editor of the Brazilian Power Electronics Journal.

Dr. Hey is a member of the Brazilian Power Electronics Society, Brazilian Automatic Control Society, and several IEEE societies. 